\title{
Vinflunine in the Treatment of Upper Tract Urothelial Carcinoma - Subgroup Analysis of an Observational Study
}

\author{
HENDRIK HEERS ${ }^{1}$, PATRICK DE GEETER ${ }^{2}$, PETER J. GOEBELL ${ }^{3}$, ULLRICH MATZ ${ }^{4}$, \\ WITO DE SCHULTZ ${ }^{5}$, BIRGIT EDLICH ${ }^{6}$, MARGITTA RETZ ${ }^{7}$ and AXEL HEGELE ${ }^{1}$ \\ ${ }^{1}$ Department of Urology/Pediatric Urology, Philipps University, Marburg, Germany; \\ ${ }^{2}$ Department of Urology, Kassel Hospital, Kassel, Germany; \\ ${ }^{3}$ Department of Urology, Friedrich-Alexander University, Erlangen, Germany; \\ ${ }^{4}$ Urologic practice, Doebeln, Germany; \\ ${ }^{5}$ Medical Urology practice, Leipzig, Germany; \\ ${ }^{6}$ Pierre Fabre Pharma GmbH, Freiburg, Germany; \\ ${ }^{7}$ Department of Urology, Technical University Munich, Munich, Germany
}

\begin{abstract}
Background/Aim: Despite an expected prognostic disadvantage for upper tract versus lower tract metastatic urothelial carcinomas (UTUC/LTUC), only few studies have been conducted to elucidate potential differences in chemotherapy treatment. Patients and Methods: A post-hoc subgroup analysis of a non-interventional study investigating vinflunine after failure of a platinum-based chemotherapy in metastatic/locally advanced UC patients was performed. Results: A total of 18 and 59 out of 77 patients had UTUC and LTUC, respectively. The effectiveness of vinflunine treatment was comparable with an overall response rate of $22.2 \%$ and $23.7 \%$ respectively and a median progressionfree survival of 2.76 months in both groups. Median overall survival was 5.0 months in UTUC compared to 8.2 months in the LTUC group $(p=0.478)$. The safety profile was in accordance with previous vinflunine experiences, with a comparable frequency of adverse events in both groups. Conclusion: Vinflunine can be applied in the 2nd line for UC regardless of the primary tumor localization.
\end{abstract}

Occupying the fifth position of the most common tumors in the worldwide cancer incidence list, urothelial carcinomas (UCs) are relatively rare tumors compared to prostate, breast, or lung

This article is freely accessible online.

Correspondence to: Prof. Dr. Axel Hegele, Department of Urology and Pediatric Urology, University Hospital Marburg, Medical School, Baldingerstraße, D-35043 Marburg. Tel: +49 (0)64215863695, Fax: +49 (0)64215865590, e-mail: hegele@ med.uni-marburg.de

Key Words: Upper tract, lower tract, urothelial carcinoma, vinflunine, UTUC, non-interventional. cancer $(1,2)$. However, the incidence of UCs is increasing, particularly in industrial countries, and will gain even more (economic) importance in the future (1-3). UCs can be subdivided in carcinomas of the lower tract (LTUC), comprising malignancies of the bladder and urethra, and carcinomas of the upper tract (UTUC), located in the pyelocaliceal cavities and ureters (1). Whereas LTUCs are quite common - approximately 356,000 new bladder cancer cases are assumed worldwide in 2012 (3) - UTUCs account for only 5$10 \%$ of UCs $(1,2)$. Moreover, about $17 \%$ of UTUC tumors are accompanied by concurrent bladder cancer (4).

Carcinomas of the lower and upper urothelial tract arise from the same urothelium and thus, it is anticipated that both cancer entities share the same tumor biology and should exhibit the same sensitivity to chemotherapy. Thus, no specific recommendations for different treatment approaches have been developed so far, regardless of treatment lines (1). UTUC treatment guidelines compiled by the European Association of Urology (EAU) state that platinum-based combination chemotherapy is expected to be efficacious in advanced UTUC although sufficient data are lacking (1). According to literature reviews on (neo-)adjuvant chemotherapy in UTUC, patients with UTUC are likely to benefit from neoadjuvant and adjuvant systemic treatment, however, the authors emphasize the need for prospective randomized trials to assess the value of systemic chemotherapy in these patients $(5,6)$.

Nevertheless, several hallmarks present in UTUC suggest a worse outcome of UTUC compared to LTUC. While only $15-25 \%$ of bladder tumors are invasive at time of diagnosis, in UTUCs this number rises to $60 \%$, usually accompanied by a higher tumor stage and tumor grade $(7,8)$. A retrospective analysis performed by Kikuchi and co-workers revealed considerable differences in metastasis incidence 
between UTUC and urothelial cancer of the bladder (UCB). Liver metastases, representing a negative prognostic factor, were counted in $22.4 \%$ (UTUC) $v s .8 .4 \%$ (UCB) of patients $(9,10)$. Furthermore, disease recurrence rates in UTUC patients were reported to be $22-47 \%$ in the bladder $(11,12)$ and $2-6 \%$ in the contralateral upper tract $(13,14)$. Localized in the upper urinary tract, these tumors hamper adequate tissue sampling under ureteroscopy and impede proper clinical staging (15). It should also be considered that the gold standard therapeutic modality for invasive UTUC is radical nephroureterectomy which often leads to an acquired loss of renal function (16).

In 2009, vinflunine was approved by the European Medicines Agency (EMA) for the treatment of locally advanced or metastatic urothelial carcinoma after failure of a platinum-based chemotherapy. Market authorization was based on a multicenter placebo-controlled phase III trial in 370 patients with locally advanced or metastatic UC who failed first-line platinum-based chemotherapy. This trial demonstrated improved patient outcomes in the eligible population: median overall survival (OS) was 6.9 months in the vinflunine group (treated with vinflunine + best supportive care (BSC)) vs. 4.3 months for the control group (BSC alone) and a $22 \%$ reduction in the risk of death $(p=0.0227)$ was observed. Overall response rate (ORR), disease control rate (DCR), and progression-free survival (PFS) were also improved under vinflunine treatment $(17,18)$.

The results of this phase III trial were confirmed in routine practice by a prospective multicenter non-interventional study (NIS) with vinflunine investigating response and tolerability of vinflunine in patients with locally advanced or metastatic LTUC and UTUC (19). More than half of the patients $(53.2 \%)$ achieved at least disease control (complete response $5.2 \%$, partial response $18.2 \%$, stable disease $29.8 \%$ ) and the median OS was 7.7 months for the entire NIS group $(17,19)$. Toxicity analyses confirmed good tolerability and the well-known safety profile of vinflunine: grade $3 / 4$ toxicities included leucopenia (16.9\%), anemia (6.5\%), elevated liver enzymes (6.5\%), and constipation (5.2\%) (19).

A subgroup analysis based on the NIS data presented above was performed to meet open issues resulting from the missing distinction between LTUC and UTUC in treatment guidelines, a low evidence for chemotherapy treatment in metastatic UTUC patients, and the lack of data on response, effectiveness, and tolerability of vinflunine in the second-line treatment of UTUC patients.

\section{Patients and Methods}

This prospective non-interventional study was reported to the competent authority and approved by the ethics committee of the scientific leader (ethics committee of the Technical University Munich, Germany). Patients with histologically confirmed locally advanced or metastatic UC who experienced failure of a prior platinum-based chemotherapy and were presenting with an Eastern Cooperative Oncology Group (ECOG) performance status of 0 or 1 were included in the documentation. A more detailed description of the study design and methods was already reported (19). Vinflunine treatment was documented according to the clinical routine for a maximum of six cycles. The main observation variables were toxicity and assessment of vinflunine treatment modalities (e.g. dosage, concomitant medication), as well as overall response rate and overall survival. The analysis was performed descriptively based on explorative methods. For continuous characteristics, arithmetic means, standard deviations and $95 \%$ confidence intervals (CI) were calculated. The one-way ANOVA (analysis of variance) test was performed to evaluate differences in baseline parameters. Efficacy parameters as mentioned above were tested for significance using log-rank tests and were described using Kaplan-Meier curves.

\section{Results}

A total of 77 evaluable patients from 39 German centers were included into the NIS from August 2010 to September 2011. Patients were deemed to be evaluable on an intent-totreat basis (ITT population). Out of the 77 patients, 18 (23\%) had UC of the upper tract and 59 patients (77\%) had LTUC (Table I). On average, UTUC patients were four years older with $30 \%$ more female patients compared to the LTUC group. However, ECOG Performance status and incidence of liver metastases were similar in both groups. Regarding other risk factors there was a slight imbalance with a higher percentage of patients with a time to treatment failure (TFPC) $<6$ months in the UTUC group from first-line chemotherapy, but more patients with hemoglobin $(\mathrm{Hb})$ values $<10 \mathrm{~g} / \mathrm{dL}$ in the LTUC group. Patients with UTUC more commonly received a lower starting dose of $\leq 280$ $\mathrm{mg} / \mathrm{m}^{2}$ vinflunine, but were treated with a similar median number of cycles.

Efficacy results were comparable between the UTUC and LTUC group (Table II). ORR was $22 \%$ in the UTUC group, and $23.7 \%$ in LTUC patients. Consistently, DCR was 50.0\% $v s .54 .2 \%$ in the UTUC and LTUC group, respectively. The median PFS was similar with 2.76 months in both groups (Figure 1A). The median OS was 5.0 months in the UTUC cohort vs. 8.2 months in the LTUC group which was statistically not significant ( $p=0.4776)$ (Figure 1B).

Overall, 272 adverse events (AEs) were documented in 55 patients $(71.4 \%), 177$ events were assessed as potentially related to vinflunine. A detailed overview of the AEs for the whole NIS population was already published (19). The safety profile was comparable between the UTUC and the LTUC group (Table III) with mainly hematological toxicities ( $\geq$ grade 3): leucopenia $27.8 \%$ (UTUC) vs. $13.6 \%$ (LTUC) and anemia $5.6 \%$ (UTUC) vs. $6.8 \%$ (LTUC). The main nonhematological toxicities grade $\geq 3$ were elevated liver enzymes $5.6 \%$ vs. $6.8 \%$ and constipation $0 \%$ vs. $6.8 \%$ in UTUC and LTUC patients, respectively. 
Table I. Baseline parameters and treatment modalities.

\begin{tabular}{|c|c|c|c|}
\hline & $\begin{array}{c}\text { Overall } \\
\mathrm{N}=77\end{array}$ & $\begin{array}{c}\text { Lower tract } \\
\mathrm{N}=59\end{array}$ & $\begin{array}{c}\text { Upper tract } \\
\mathrm{N}=18\end{array}$ \\
\hline \multicolumn{4}{|l|}{ Gender, n (\%) } \\
\hline Male & $63(81.2)$ & $53(89.8)$ & $10(55.6)$ \\
\hline Female & $14(18.2)$ & $6(10.2)$ & $8(44.4)$ \\
\hline Median age in years (range) & $67(39-80)$ & $67(39-80)$ & $70(51-79)$ \\
\hline \multicolumn{4}{|l|}{ ECOG PS, n (\%) } \\
\hline 0 & $35(45.5)$ & $27(45.8)$ & $8(44.4)$ \\
\hline 1 & $42(54.6)$ & $32(54.2)$ & $10(55.6)$ \\
\hline Visceral involvement, $\mathrm{n}(\%)$ & $46(59.7)$ & $35(59.3)$ & $11(61.1)$ \\
\hline Liver metastases ${ }^{\dagger}, \mathrm{n}(\%)$ & $17(26.2)$ & $13(26.5)$ & $4(25.0)$ \\
\hline TFPC $<6$ months ${ }^{\ddagger}, \mathrm{n}(\%)$ & $54(70.1)^{*}$ & $40(67.8)^{*}$ & $14(77.8)^{*}$ \\
\hline Mean $\mathrm{Hb}$ in $\mathrm{g} / \mathrm{dL} \S$ & 11.24 & 11.27 & 11.16 \\
\hline $\mathrm{Hb}<10 \mathrm{~g} / \mathrm{dL}^{\S}, \mathrm{n}(\%)$ & $13(18.8)$ & $11(20.8)$ & $2(12.5)$ \\
\hline Median number of cycles (range) & $4(1-6)$ & $4(1-6)$ & $4(1-6)$ \\
\hline \multicolumn{4}{|l|}{ Starting dose, $\mathrm{n}(\%)$} \\
\hline $320 \mathrm{mg} / \mathrm{m}^{2}$ & $37(48.0)$ & $33(55.9)$ & $4(22.2)$ \\
\hline$\leq 280 \mathrm{mg} / \mathrm{m}^{2}$ & $40(52.0)$ & $26(44.1)$ & $14(77.8)$ \\
\hline
\end{tabular}

ECOG 0: Karnofsky Performance Status 90-100\%; ECOG 1: Karnofsky Performance Status 70-80\%. ECOG PS: Eastern Cooperative Oncology Group Performance Status; TFPC: time to treatment failure; $\mathrm{Hb}$ : hemoglobin. *time to registration; †information missing for 4 patients in the $320 \mathrm{mg} / \mathrm{m}^{2}$ group and 8 patients in the $\leq 280 \mathrm{mg} / \mathrm{m}^{2}$ group; \#information missing for 6 patients in the $320 \mathrm{mg} / \mathrm{m}^{2}$ group and 2

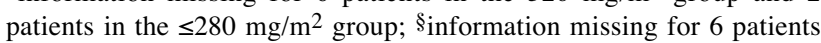
in the $320 \mathrm{mg} / \mathrm{m}^{2}$ group and 2 patients in the $\leq 280 \mathrm{mg} / \mathrm{m}^{2}$ group.

\section{Discussion}

As UTUC patients usually present various hallmarks which are assumed to have a negative impact on patient outcome, differences in response and/or survival outcomes between UTUC and LTUC patients may be expected. Usually, UTUC patients showed worse prognostic factors at the time of diagnosis with higher tumor stage and grade together with a higher age (7-9). Notably, the impaired renal function with a low glomerular filtration rate (GFR) after standard radical nephroureterectomy (16) can lead to a less effective chemotherapy as patients may be ineligible for a cisplatinbased regimen. Nevertheless, both tumor entities arise from the same transitional epithelium tissue, leading to the assumption that tumors of the upper urinary tract should - in analogy to bladder tumors - be amenable to chemotherapy as well.

Current literature does not provide sufficient data to establish UTUC treatment guidelines with a high grade of evidence due to the scarcity of prospective clinical trials. Although the focus on UTUC has increased lately, most analyses are retrospective and patient collectives are small owing to the rarity of the disease.

As already reported by Retz et al. (19), the prospective noninterventional study presented here has confirmed that UC patients benefit from treatment with vinflunine in the second
Table II. Tumor response to vinflunine treatment.

\begin{tabular}{lccc}
\hline & Overall $(\mathrm{n}=77)$ & LTUC $(\mathrm{n}=59)$ & UTUC $(\mathrm{n}=18)$ \\
\hline Complete response & $4(5.2 \%)$ & $3(5.1 \%)$ & $1(5.6 \%)$ \\
Partial response & $14(18.2 \%)$ & $11(18.6 \%)$ & $3(16.7 \%)$ \\
Stable disease & $23(29.9 \%)$ & $18(30.5 \%)$ & $5(27.8 \%)$ \\
Progressive disease & $31(40.3 \%)$ & $24(40.7 \%)$ & $7(38.9 \%)$ \\
Overall response rate & $18(23.4 \%)$ & $14(23.7 \%)$ & $4(22.2 \%)$ \\
Disease control rate & $41(53.2 \%)$ & $32(54.2 \%)$ & $9(50 \%)$ \\
\hline
\end{tabular}

LTUC: Lower tract urothelial carcinoma, UTUC: upper tract urothelial carcinoma.

line after failure of a platinum-based therapy regime. Tumor response as well as the safety and tolerability profile of vinflunine are comparable for both tumor localizations. No significant difference regarding overall survival was observed. These findings strengthen the approach to apply similar therapy regimen to tumors of the upper and the lower urothelial tract. Our observations are in accordance with the results of a retrospective cohort analysis performed by Kikuchi and colleagues who evaluated 216 patients treated with cisplatinbased chemotherapy regimens in the first-line setting. They pointed out that there is a significantly higher incidence of lung and liver metastases in UTUC compared to LTUC patients and that the estimated GFR at baseline is significantly lower in UTUC patients. However, no significant difference in ORR under systemic chemotherapy in the first-line was observed (9). Our data suggest that the same observation holds true for the second-line setting: PFS and ORR were comparable between both groups with a numerically longer OS in LTUC (8.2 vs. 5.0 months) that might be explained by the higher percentage of LTUC patients receiving a starting dose of $320 \mathrm{mg} / \mathrm{m}^{2}$ vinflunine ( $55.9 \%$ vs. $22.2 \%$ ). Hence, vinflunine treatment can be applied - as recommended by current EAU guidelines (1) - in the second line regardless of primary tumor localization.

Both subgroups confirmed the well characterized safety profile of vinflunine. Despite the higher probability of reduced GFR in UTUC patients $(9,16)$, the toxicities reported in this prospective NIS were well balanced between the two groups. Dose reduction recommendations as provided in the Summary of Product Characteristics (SmPC) might account for the good tolerability of vinflunine, especially with reference to antiemetic and laxative prophylaxis.

Owing to the non-interventional nature of this study there are several limitations, such as missing control over patient management and tumor assessments and the lack of intervention specifications. Thus, PFS and efficiency data should be interpreted with caution. Incidence of AEs might be underestimated, as no visit schedule is dictated and actual visits might be performed less frequently. Moreover, another limitation is the small patient collective - on account of the 
A

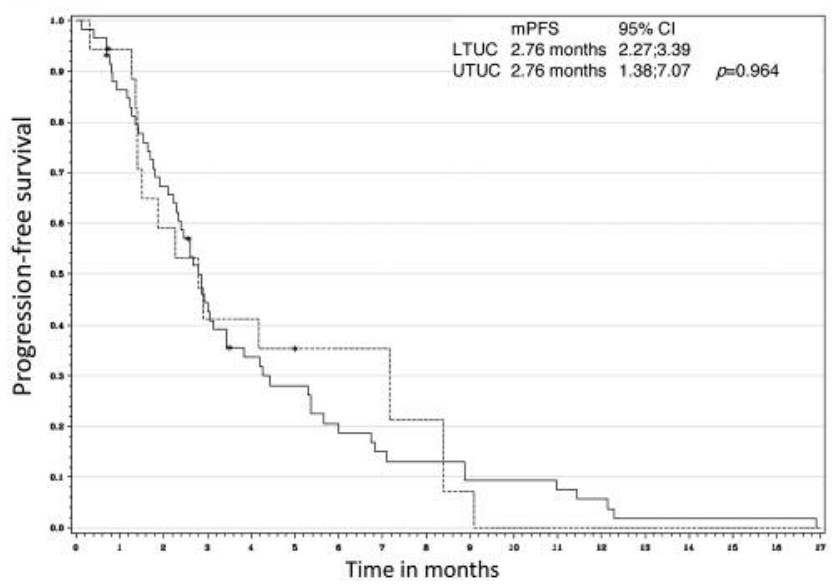

B

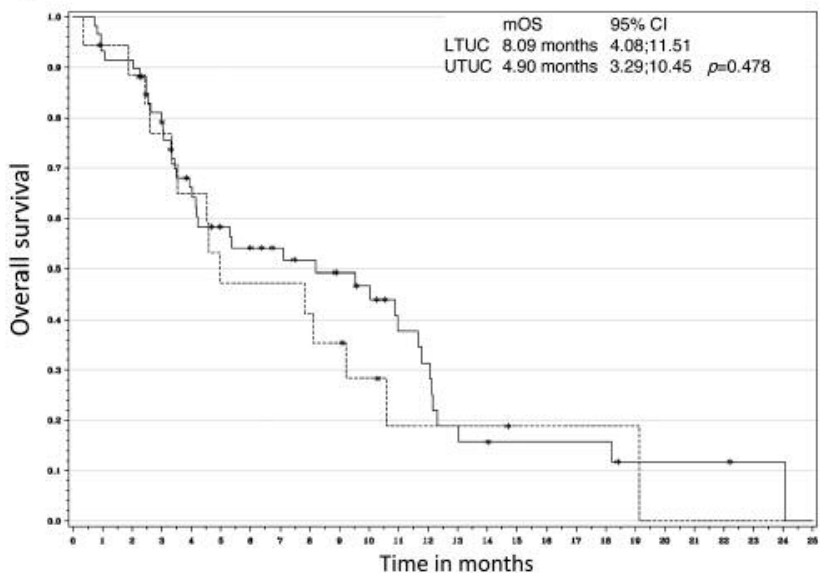

Figure 1. Progression-free survival (A) and overall survival (B) of patients with upper tract urothelial cancer (broken line) and lower tract urothelial cancer (solid line). mPFS: median progression-free survival; mOS: Median overall survival; CI: confidence interval; LTUC: lower tract urothelial carcinoma; UTUC: upper tract urothelial carcinoma.

Table III. Adverse reactions related to vinflunine per max. NCI-CTCAE grade (ITT population).

\begin{tabular}{|c|c|c|c|c|c|c|}
\hline & \multicolumn{2}{|c|}{$\begin{array}{l}\text { Overall }(\mathrm{n}=77) \\
\quad \geq \text { grade } 3\end{array}$} & \multicolumn{2}{|c|}{$\begin{array}{c}\text { Lower tract }(\mathrm{n}=59) \\
\geq \text { grade } 3\end{array}$} & \multicolumn{2}{|c|}{$\begin{array}{c}\text { Upper tract }(\mathrm{n}=18) \\
\geq \text { grade } 3\end{array}$} \\
\hline & $\mathrm{n}$ & $\%$ & $\mathrm{n}$ & $\%$ & $\mathrm{n}$ & $\%$ \\
\hline Leucopenia & 13 & 16.9 & 8 & 13.6 & 5 & 27.8 \\
\hline Anemia & 5 & 6.5 & 4 & 6.8 & 1 & 5.6 \\
\hline Thrombocytopenia & 1 & 1.3 & 1 & 1.7 & 0 & 0.0 \\
\hline Neutropenia & 1 & 1.3 & 1 & 1.7 & 0 & 0.0 \\
\hline Elevated liver enzymes* & 3 & 3.9 & 2 & 3.4 & 1 & 5.6 \\
\hline Fatigue & 1 & 1.3 & 1 & 1.7 & 0 & 0.0 \\
\hline Pain & 2 & 2.6 & 2 & 3.4 & 0 & 0.0 \\
\hline Constipation & 4 & 5.2 & 4 & 6.8 & 0 & 0.0 \\
\hline Nausea & 2 & 2.6 & 1 & 1.7 & 1 & 5.6 \\
\hline Constitutional symptoms & 3 & 3.9 & 2 & 3.4 & 1 & 5.6 \\
\hline Infection & 4 & 5.2 & 4 & 6.8 & 0 & 0.0 \\
\hline Vomiting & 2 & 2.6 & 1 & 1.7 & 1 & 5.6 \\
\hline Neutropenic infection & 1 & 1.3 & 1 & 1.7 & 0 & 0.0 \\
\hline
\end{tabular}

*GGT, AST, ALT and/or alkaline phosphatase. ITT: intent-to-treat.

low prevalence and incidence of the disease, this is a common limitation of most UC studies. Considering additionally the scarcity of controlled clinical trials in these patients, non-interventional studies and retrospective analyses all the more contribute to valid efficiency and safety evaluations of treatment modalities and thus are important tools for the development of treatment recommendations.

In comparison, several non-interventional studies focusing on vinflunine treatment after platinum-based chemotherapy have been conducted in other European countries and showed comparable results (21-26). Most frequently reported grade 3/4 AEs were neutropenia (2-23\%), anemia (4-33\%), fatigue (1-36\%), and constipation (5-22\%).

Vinflunine is an efficacious treatment option for UC patients with manageable toxicities. Moreover, these first data on vinflunine treatment in UTUC and LTUC show no significant differences regarding tumor response rates, survival, and adverse events. In conclusion, vinflunine can be applied in UC patients as a second-line treatment option regardless of tumor localization. 


\section{Acknowledgements}

The Authors would like to thank all participating centers. Furthermore, the Authors thank Anna Resch for medical writing support, which was financed by Pierre Fabre Pharma GmbH.

\section{References}

1 Rouprêt M, Babjuk M, Burger M, Compérat E, Cowan N, Gontero P, Mostafid AH, Palou J, van Rhijn BWG, Shariat SF, Sylvester R and Zigeuner R: European association of urology guidelines on upper urinary tract urothelial cell carcinoma Available at : http://uroweb.org/guideline/upper-urinary-tracturothelial-cell-carcinoma/?type=summary-of-changes, accessed 30-05-2017.

2 Munoz JJ and Ellison LM: Upper tract urothelial neoplasms: Incidence and survival during the last 2 decades. J Urol 164(5): 1523-1525, 2000

3 Ploeg M, Aben, Katja KH and Kiemeney LA: The present and future burden of urinary bladder cancer in the world. World J Urol 27(3): 289-293, 2009.

4 Cosentino M, Palou J, Gaya JM, Breda A, Rodriguez-Faba O and Villavicencio-Mavrich $\mathrm{H}$ : Upper urinary tract urothelial cell carcinoma: location as a predictive factor for concomitant bladder carcinoma. World J Urol 31(1): 141-145, 2013.

5 Aziz A, Dobruch J, Hendricksen K, Kluth LA, Necchi A, Noon A, Rink M, Roghmann F, Seiler R, Gontero P, Kassouf W, Shariat SF and Xylinas E: Perioperative chemotherapy in upper tract urothelial carcinoma: a comprehensive review. World J Urol, 2017. doi: 10.1007/s00345-016-1995-z. [Epub ahead of print]

6 Gayed BA, Thoreson GR and Margulis V: The role of systemic chemotherapy in management of upper tract urothelial cancer. Curr Urol Rep 14: 94-101, 2013.

7 Margulis V, Shariat SF, Matin SF, Kamat AM, Zigeuner R, Kikuchi E, Lotan Y, Weizer A, Raman JD, Wood CG and the Upper Tract Urothelial Carcinoma Collaboration: Outcomes of radical nephroureterectomy: A series from the Upper Tract Urothelial Carcinoma Collaboration. Cancer 115(6): 1224-1233, 2009.

8 Catto JWF, Yates DR, Rehman I, Azzouzi AR, Patterson J, Sibony M, Cussenot O and Hamdy FC: Behavior of urothelial carcinoma with respect to anatomical location. J Urology 177(5): 1715-1720, 2007

9 Kikuchi E, Miyazaki J, Yuge K, Hagiwara M, Ichioka D, Inoue T, Kageyama S, Sugimoto M, Mitsuzuka K, Matsui Y, Yamamoto S, Kinoshita H, Wakeda H, Hanai K and Nishiyama $\mathrm{H}$ : Do metastatic upper tract urothelial carcinomas and bladder carcinoma have similar clinical responses to systemic chemotherapy? A Japanese multi-institutional experience. Jpn J Clin Oncol: 1-7, 2015.

10 Bellmunt J, Choueiri TK, Fougeray R, Schutz FAB, Salhi Y, Winquist E, Culine S, von der Maase H, Vaughn DJ and Rosenberg JE: Prognostic factors in patients with advanced transitional cell carcinoma of the urothelial tract experiencing treatment failure with platinum-containing regimens. J Clin Oncol 28(11): 1850-1855, 2010

11 Xylinas E, Rink M, Margulis V, Karakiewicz P, Novara G and Shariat SF: Multifocal carcinoma in situ of the upper tract is associated with high risk of bladder cancer recurrence. Eur Urol 61(5): 1069-1070, 2012.
12 Zigeuner RE, Hutterer G, Chromecki T, Rehak P and Langner $\mathrm{C}$ : Bladder tumour development after urothelial carcinoma of the upper urinary tract is related to primary tumour location. BJU Int 98(6): 1181-1186, 2006

$13 \mathrm{Li}$ WM, Shen JT, Li CC, Ke HL, Wei YC, Wu WJ, Chou YH and Huang $\mathrm{CH}$ : Oncologic outcomes following three different approaches to the distal ureter and bladder cuff in nephroureterectomy for primary upper urinary tract urothelial carcinoma. Eur Urol 57(6): 963-969, 2010.

14 Novara G, de Marco V, Dalpiaz O, Galfano A, Bouygues V, Gardiman M, Martignoni G, Patard JJ, Artibani W and Ficarra V: Independent predictors of contralateral metachronous upper urinary tract transitional cell carcinoma after nephroureterectomy: Multi-institutional dataset from three European centers. International Journal of Urology 16(2): 187-191, 2009.

15 Smith AK, Stephenson AJ, Lane BR, Larson BT, Thomas AA, Gong MC, Jones JS, Campbell SC and Hansel DE: Inadequacy of biopsy for diagnosis of upper tract urothelial carcinoma: Implications for conservative management. Urology 78(1): 82-86, 2011.

16 Xylinas E, Rink M, Margulis V, Clozel T, Lee RK, Comploj E, Novara G, Raman JD, Lotan Y, Weizer A, Roupret M, Pycha A, Scherr DS, Seitz C, Ficarra V, Trinh QD, Karakiewicz PI, Montorsi F, Zerbib M and Shariat SF: Impact of renal function on eligibility for chemotherapy and survival in patients who have undergone radical nephro-ureterectomy. BJU Int 112(4): 453-461, 2013.

17 Bellmunt J, Théodore C, Demkov T, Komyakov B, Sengelov L, Daugaard G, Caty A, Carles J, Jagiello-Gruszfeld A, Karyakin O, Delgado FM, Hurteloup P, Winquist E, Morsli N, Salhi Y, Culine $\mathrm{S}$ and von der Maase $\mathrm{H}$ : Phase III trial of vinflunine plus best supportive care compared with best supportive care alone after a platinum-containing regimen in patients with advanced transitional cell carcinoma of the urothelial tract. J Clin Oncol 27(27): 4454-4461, 2009

18 Bellmunt J, Fougeray R, Rosenberg JE, von der Maase H., Schutz FA, Salhi Y, Culine S and Choueiri TK: Long-term survival results of a randomized phase III trial of vinflunine plus best supportive care versus best supportive care alone in advanced urothelial carcinoma patients after failure of platinumbased chemotherapy. Ann Oncol 24(6): 1466-1472, 2013.

19 Retz M, de Geeter P, Goebell PJ, Matz U, de Schultz W and Hegele A: Vinflunine in routine clinical practice for the treatment of advanced or metastatic urothelial cell carcinoma - data from a prospective, multicenter experience. BMC Cancer 15: 455, 2015.

20 Witjes JA, Compérat E, Cowan NC, De Santis M, Gakis G, Lebrét T, Ribal MJ, Sherif A and van der Heijden AG : EAU guidelines on muscle-invasive and metastatic bladder cancer: summary of the 2013 guidelines. Eur Urol 65(4): 778-792, 2014.

21 Médioni J, Di Palma M, Guillot A, Spaeth D and Théodore C: Efficacy and safety of Vinflunine for advanced or metastatic urothelial carcinoma in routine practice based on the French multi-centre CURVE study. BMC Cancer 16: 217, 2016.

22 Pistamaltzian N, Tzannis K, Pissanidou V, Peroukidis S, Milaki G, Karavasilis V, Mitsogiannis I, Varkarakis I, Papatsoris A, Dellis A, Adamakis I, Stravodimos K, Molyva D, Athanasiadis I, Androulakis N, Andreadis C, Kalofonos C, Mitropoulos D, Deliveliotis C, Constantinides C, Dimopoulos MA and Bamias A: Treatment of relapsed urothelial bladder cancer with vinflunine: real-world evidence by the Hellenic Genitourinary Cancer Group. Anti-Cancer Drugs 27: 48-53, 2016. 
23 Holmsten K, Dohn LH, Jensen NV, Shah CH, Jäderling F, Pappot $\mathrm{H}$ and Ullén A: Vinflunine treatment in patients with metastatic urothelial cancer: A Nordic retrospective multicenter analysis. Oncol Lett 12(2): 1293-1300, 2016.

24 Hussain SA, Ansari J, Huddart R, Power DG, Lyons J, Wylie J, Vilarino-Varlela M, Elander NO, McMenemin R, Pickering LM, Faust G, Chauhan S and Jackson RJ: VICTOR: Vinflunine in advanced metastatic transitional cell carcinoma of the urothelium: A retrospective analysis of the use of vinflunine in multi-centre real life setting as second line chemotherapy through Free of Charge Programme for patients in the UK and Ireland. Int J Oncol 50(3): 768-772, 2017.

25 Passalacqua R, Lazzarelli S, Montironi R, Tambaro R, De Giorgi U, Bernardo A, Ceresoli GL, Del Conte G, Donini M, Iezzi E, Morelli F, Nole F, Panni S, Perrucci B, Rondini E, Sabbatini R, Sequino M, Tonini G, Zucali PA and Caminiti C: Vinflunine
(VFL) in patients (pts) with metastatic transitional cell carcinoma of the urothelial tract (mTCCU): Clinical outcome and prognostic factors in a nationwide, real-life setting (MOVIE trial). J Clin Oncol 34: abstr e16031, 2016.

26 Castellano D, Puente J, de Velasco G, Chirivella I, López-Criado P, Mohedano N, Fernández O, García-Carbonero I, González $\mathrm{MB}$ and Grande E: Safety and effectiveness of vinflunine in patients with metastatic transitional cell carcinoma of the urothelial tract after failure of one platinum-based systemic therapy in clinical practice. BMC Cancer 14: 779, 2014.

Received June 21, 2017

Revised July 5, 2017

Accepted July 7, 2017 